\title{
Transcriptional Activation of the Alpha-1 Acid Glycoprotein Gene by YY1 Is Mediated by Its Functional Interaction with a Negative Transcription Factor
}

\author{
YU-MAY LEE and SHENG-CHUNG LEE
}

\begin{abstract}
Regulation of alpha-1 acid glycoprotein (AGP) gene expression involves both positive and negative transcription factors. We have previously identified two dominant factors: positive and negative transcription factors, AGP/EBP and factor B, respectively, involved in the transcription of AGP and other acute-phase response genes. In this report, we present evidence showing that the transcription of the AGP gene is positively regulated by a transcription factor, YY1. The activation of AGP gene by YY1 is mediated by a negative element $B$ in the AGP promoter region. YY1 can also activate the B motif linked to a heterologous promoter. However, YY1 does not bind directly to the B motif per se. Rather, our data suggest that the activation of AGP gene by YY1 may be mediated by its functional interaction with factor $B$, which recognizes the $B$ motif.
\end{abstract}

\section{INTRODUCTION}

A LPHA-1 ACID GLYCOPROTEIN (AGP) is one of the most abundant, acute-phase-responsive, liver-specific plasma proteins. The biological function of AGP is unknown, but there are indications that it may suppress the immune response (Bennett and Schmid, 1980). Some experiments suggest that AGP is a nonspecific antiinfection agent (Friedmann, 1983), and that it possesses nerve growthpromoting activity (Liu et al., 1988). To investigate the regulation of AGP gene expression during physiological homeostasis and during perturbed physiological conditions (i.e., acute inflammation), it is essential to study the complex interactions of various trans-acting factors in these different physiological states.

In rats and mice, the levels of liver AGP mRNA and plasma AGP protein increase 10- to 100 -fold within $24 \mathrm{hr}$ of experimentally induced inflammation (Baumann and Held, 1981; Baumann et al., 1983, Kulkarni et al., 1985; Baumann and Maquat 1986; Darlington et al., 1986; Gauldi et al., 1987; Klein et al., 1988; Prowse and Baumann, 1988). The increase in mRNA is primarily attributed to transcriptional activation of the AGP gene (Kulkarni et al., 1985; Baumann and Maquat, 1986). We have previously identified four motifs recognized by a positive transcription factor, AGP/ EBP, and a negative cis element recognized by a negative factor (i.e., factor B) (Chang et al., 1990; Lee et al., 1993). During the acute-phase response, there is dramatic increase in the level of AGP/EBP, coupled to the decrease in factor B, resulting in the induction of AGP gene transcription (Lee $e t$ al., 1993). In addition to AGP/EBP and factor B, glucocorticoids (Klein et al., 1988) have also been shown to be involved in the induction of AGP gene. Despite the substantial progress in understanding the factors in regulating the activation of AGP gene during the acute-phase response, the regulation of this gene in normal physiological states remains to be investigated.

The upstream regulatory region of the AGP gene contains a sequence, GAACATT TT $(-121$ to -113$)$ that is similar to a motif recognized by a transcription factor, YY 1 (consensus sequence, CGACATTTT) (Shi et al., 1991). YY1 is a human Krüppel-related protein that interacts with DNA elements (CGACATTTT, located at -50 to -70 ; CTCCATTTT, located at the transcription initiation site) of the adeno-associated virus P5 promoter. These DNA elements are capable of repressing transcription directed by heterolo-

Institute of Biological Chemistry, Academia Sinica, and Institute of Molecular Medicine, and Institute of Clinical Medicine, College of Medicine, National Taiwan University, Taipei, Taiwan. 
gous promoters. E1A not only relieves repression exerted by YY1 but also stimulates transcription through the YY1 binding site (Shi et al., 1991). There is evidence that YY1 mediates both the repression and activation responses (Shi $e t$ $a l ., 1991)$. The ability of YY1 to mediate opposite effects depends on the intracellular milieu (e.g., the presence or absence of E1A). YY1 is related to the GL1-Krüppel family of genes (Ruppert et al., 1988). The Drosophila Krüppel protein can also repress or activate transcription, depending on the context of its binding site (Frasch and Levine, 1987; Ruppert et al., 1988; Licht et al., 1990). Two different domains in the Krüppel protein have been reported to exhibit repression activity when fused to a heterologous DNAbinding domain. It remains to be determined whether the Krüppel protein contains an activation domain. In addition to YY1, several transcription factors identical or homologous to $Y Y 1$ have been identified and cloned. Among them are: protein delta, which binds to sequence elements (GCNGCCATC) downstream of the transcriptional start sites in ribosomal protein genes and functions as an activator (Hariharan et al., 1991); NF-E1, which binds to the IgK 3' enhancer (CCACCTCCATCTT) and functions as a repressor (Park and Atchison, 1991); UCRBP, which binds to the UCR core (CGCCATTTT) in the long terminal repeat of Moloney leukemia virus (which also functions as a repressor) (Flanagan et al., 1992); and F-ACT1, which binds competitively to the most proximal serum response element (CGCCATATT) of the skeletal $\alpha$-actin gene and functions as a repressor (Lee et al., 1992). These data indicate that the binding specificity of YY1 or its homolog is unusually diverse. Furthermore, a negative regulatory domain in the human papillomavirus type 18 promoter was shown to be the target site of YY1 (Bauknecht et al., 1992). Taken together, these data suggest that, depending on the context, YYl can function as an activator, a repressor, or an initiator of transcription. For these reasons, we decided to investigate the possible involvement of the YY1-like motif in the regulation of AGP gene expression. In this study we examined the regulation of wild-type and a series of mutants of AGP promoter in transient transfection assays. We found that YY1 can activate AGP promoter by relieving the negative action of $B$ element, located at -40 to -66 . However, YY1 did not bind directly to this negative element. Instead, it relieves the repression of AGP gene by its functional interaction with factor $B$.

\section{MATERIALS AND METHODS}

\section{Preparation of nuclear extract}

Liver nuclear extract was prepared according to the procedures of Gorski et al. (1986) from 200- to 300-gram Wistar rats either untreated or treated with lipopolysaccharide (LPS) ( $10 \mu \mathrm{g} / \mathrm{gram}$ body weight) for $4 \mathrm{hr}$. Detailed procedures were as described (Gorski et al., 1986).

\section{Plasmids and oligonucleotides}

The AGP/CAT, AGP/EBP/CAT, and CMV-AGP/EBP were as described (Chang et al., 1990; Lee et al., 1993).
CMV-YY1 (kindly provided by Dr. T. Shenk) was detailed elsewhere (Shi et al., 1991). Various CAT constructs containing the mutated AGP promoter sequence were generated essentially as described (Lee et al., 1993). pCAT-promoter (CAT reporter gene controlled by SV40 promoter) and pSV- $\beta$-Gal ( $\beta$-galactosidase reporter gene controlled by SV40 promoter) were obtained from Promega (WI). These two reporter vectors were used for constructing the recombinant plasmids containing the oligomeric B motif. All the constructs were verified by sequence analysis. The oligonucleotides used were as follows: B, TACTGTCCCTGGCTTCAGTCCCATGCCCT; U (UCR), TAACGCCATTTTGCAAGGCAT; mutant UCR (mt U); TAAATACATTTTGCAAGGCAT.

\section{Analysis of protein-DNA interaction}

Gel mobility-shift and footprinting assays were as described (Lee et al., 1993). Briefly, an end-labeled DNA fragment $(-180$ to +10 from AGP promoter region) $(5 \mathrm{ng})$ generated by polymerase chain reactions (PCR) was added to a $20-\mu \mathrm{l}$ reaction mixture containing $50 \mathrm{mM} \mathrm{NaCl}, 20 \mathrm{~m} M$ Tris- $\mathrm{HCl} \mathrm{pH} 7.6,1 \mathrm{mM} \mathrm{MgCl}_{2}, 0.2 \mathrm{mM}$ EDTA, $10 \%$ glycerol, $5 \mathrm{mM}$ DTT, and $1 \mu \mathrm{g}$ poly(dI-dC). Nuclear extract or partially purified fraction containing factor $B$ was preincubated with recombinant $Y Y 1$ or partially purified YY1 for $5 \mathrm{~min}$ at room temperature followed by adding the probe and incubated for $90 \mathrm{~min}$ on ice. DNase I $(30 \mu \mathrm{g} / \mathrm{ml}$, Sigma $)$ freshly diluted in $10 \mathrm{mM} \mathrm{MgCl}$ and $5 \mathrm{mMCaCl} \mathrm{Cas}_{2}$ wadded to the reaction mixture (usually $1-3 \mu \mathrm{l}$ was used). Digestion was performed for 2-3 min on ice and stopped by the addition of $80 \mu \mathrm{l}$ of stop solution containing $75 \mu \mathrm{g}$ of yeast tRNA $/ \mathrm{ml}$, $20 \mathrm{mM}$ EDTA, and $0.5 \% \mathrm{NaDodSO}_{4}$. The samples were extracted with phenol chloroform, precipitated with ethanol at $-70^{\circ} \mathrm{C}$. The pellets were dried and resuspended in sequencing solution ( $95 \%$ formamide, $1 \%$ xylene cyanol $\mathrm{FF}$, and $1 \%$ bromphenol blue), heated at $95^{\circ} \mathrm{C}$ for $3 \mathrm{~min}$, and loaded onto a sequencing gel.

For gel mobility-shift assays, protein-DNA complexes were formed as described for the footprinting assays. After incubation for $20 \mathrm{~min}$ at room temperature, $1 \mu \mathrm{l}$ of $1 \%$ bromphenol blue was added, and the sample was loaded onto a $5 \%$ polyacrylamide gel (acrylamide/bisacrylamide $=$ 30:1) containing $4 \%$ glycerol in Tris-Glycin buffer. Electrophoresis was performed at $150 \mathrm{~V}$ at room temperature with buffer circulation.

\section{Recombinant YYI and antibody to $Y Y I$}

Recombinant YY1 was generated by cloning the Nco I-Eco RI fragment of YY1 cDNA (YY1 plasmid was kindly provided by Dr. T. Shenk, Princeton University) into plasmid pRSET (Invitrogen, San Diego, CA). The recombinant YY1 expressed in Escherichia coli [BL21 (DE3)] was purified by Ni column and detected by Western blot using rabbit polyclonal anti-YY1. Rabbit anti-YY1 was generated by immunizing the antigen expressed in $E$. coli. Briefly, a cDNA fragment corresponding to polypeptide of 232 amino acids containing the carboxy-terminal part of $Y Y 1$ was cloned by PCR from human placenta cDNA library. The 
sequence was verified by sequence analysis. The cDNA fragment was cloned into pRSET (Invitrogen, San Diego, $\mathrm{CA})$ and expressed in BL21(DE3).

\section{Cell cultures, DNA transfections, and CAT assays}

Baby hamster kidney (BHK) cells were cultured in Dulbecco's modified Eagle's medium supplemented with $10 \%$ fetal calf serum. DNA transfections were performed by the calcium phosphate precipitation technique. For each $10-\mathrm{cm}$ petri dish, the calcium phosphate-DNA precipitate contained $8 \mu \mathrm{g}$ of target plasmid, and $3 \mu \mathrm{g}$ CMV-YY 1 or amino-terminal deleted YY1 (CMV-C250), which contains the carboxy-terminal 250 amino acids. Plasmid pGEM4 was used as a carrier to make the final DNA to be $15 \mu \mathrm{g}$. Cells were harvested $48 \mathrm{hr}$ post-transfection. Cell extract $(30 \mu \mathrm{g})$ was used for CAT assay. CAT activity was quantitated by densitometric scanning of the autoradiogram or by scanning of the TLC plate with BioRad Image analysis system.

\section{Western blot analysis}

Rat liver nuclear extracts were prepared as described (Chang et al., 1990). Liver nuclear extracts were obtained from control and LPS-treated Wistar rats. Varying amounts of nuclear extracts were resolved on a $10 \% \mathrm{NaPodSO}_{4}$ polyacrylamide gel. Proteins were electroblotted to nitrocellulose membrane. The protein blot was subjected to standard Western blot development using rabbit anti-YYl and goat anti-rabbit IgG alkaline phosphatase conjugate.

\section{RESULTS}

\section{Transcriptional activation of $A G P$ promoter by $Y Y I$}

To investigate the possible involvement of YY1 in AGP gene regulation, we initiated functional and biochemical characterizations of $\mathrm{YY} 1$ on AGP regulation. BHK cells were used for the transfection assays because BHK and HepG2 cells behaved similarly as demonstrated by our previous studies (Lee et al., 1993). Transfection of wild-type and several mutants of AGP-CAT together with CMV-YY 1 showed that YY1 could activate AGP promoter (Fig. 1). Mutations in the sequence, GAACATTTT, do not have any effect on YYl's activation. These results indicate that YY1 can activate AGP transcription, but independently of the sequence, GAACATTTT. Further experiments by gel mobility-shift or footprinting assay using recombinant YY1 derived from $E$. coll have failed to show that YY 1 could bind to this sequence (data not shown). Having demonstrated that YYl could trans-activate AGP gene, we tested its possible interaction with the most prominant activator for AGP gene, AGP/EBP. It turned out that activation of AGP gene by YY 1 and AGP/EBP is additive (Fig. 2). Therefore, the activation of AGP gene by YY1 and AGP/EBP are independent event. To understand the implications of these data further, we generated a series of mutants spanning from -140 to -94 and a B-element-truncated mutant (Lee et al., 1993). The nucleotide sequence and the co-transfection data are shown in Fig. 3. YY 1 could activate wild-type as well as every
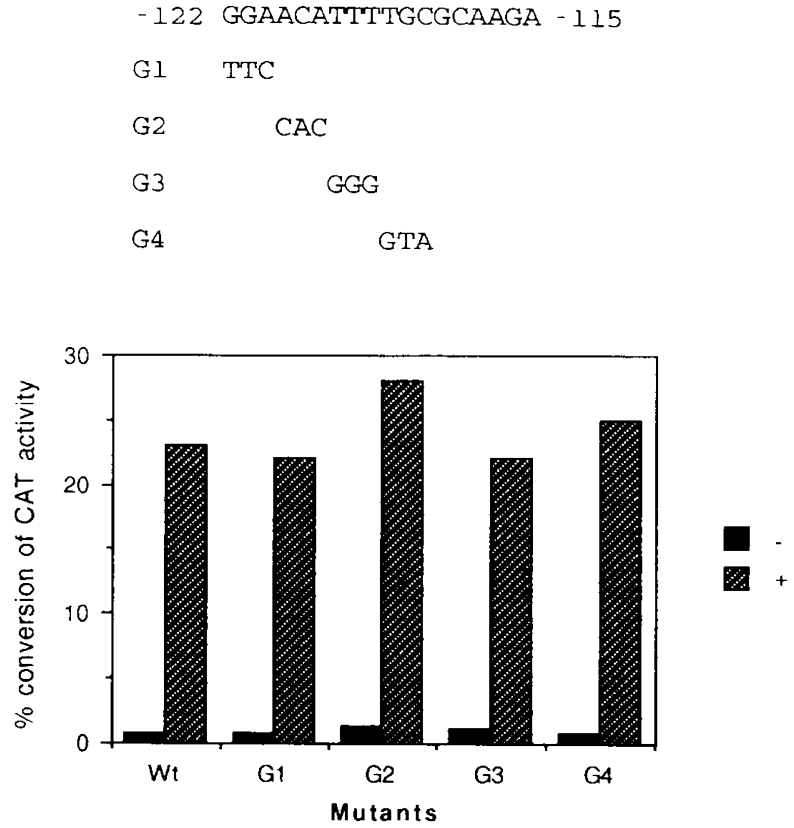

FIG. 1. Trans-activation of the AGP gene by YY1. Cotransfection assays of CMV-YY1 expression vector and wild-type and mutated AGP sequences linked to CAT reporter gene. The upstream regulatory sequence $(-122$ to -155) of the AGP gene and the corresponding mutants are shown in the upper panel. The results of CAT assay are shown in the lower panel. CMV-YYl $(3 \mu \mathrm{g})$ and $10 \mu \mathrm{g}$ of reporter gene were cotransfected into BHK cells. (-) Cells transfected with reporter gene without CMV-YY1; (+) cotransfected with CMV-YY1.

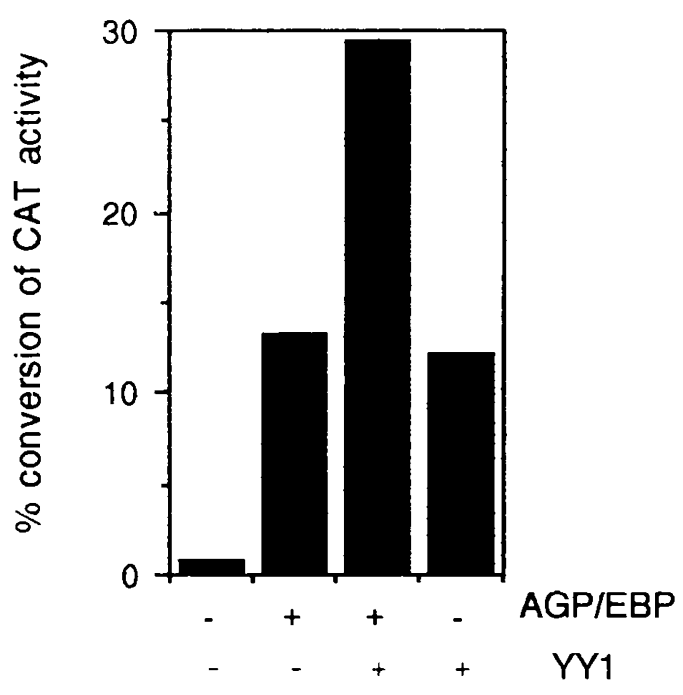

FIG. 2. The activation of AGP promoter function by AGP/EBP and YY-1 is additive. AGP/CAT, CMV-YYl, and $\mathrm{CMV}-\mathrm{AGP} / \mathrm{EBP}$ were detailed in the previous section or elsewhere. BHK cells were used for the transfection assays. AGP/CAT $(10 \mu \mathrm{g})$ and $1 \mu \mathrm{g}$ of CMV-YY 1 and/or CMV$\mathrm{AGP} / \mathrm{EBP}$ were used for the transfection assay. 

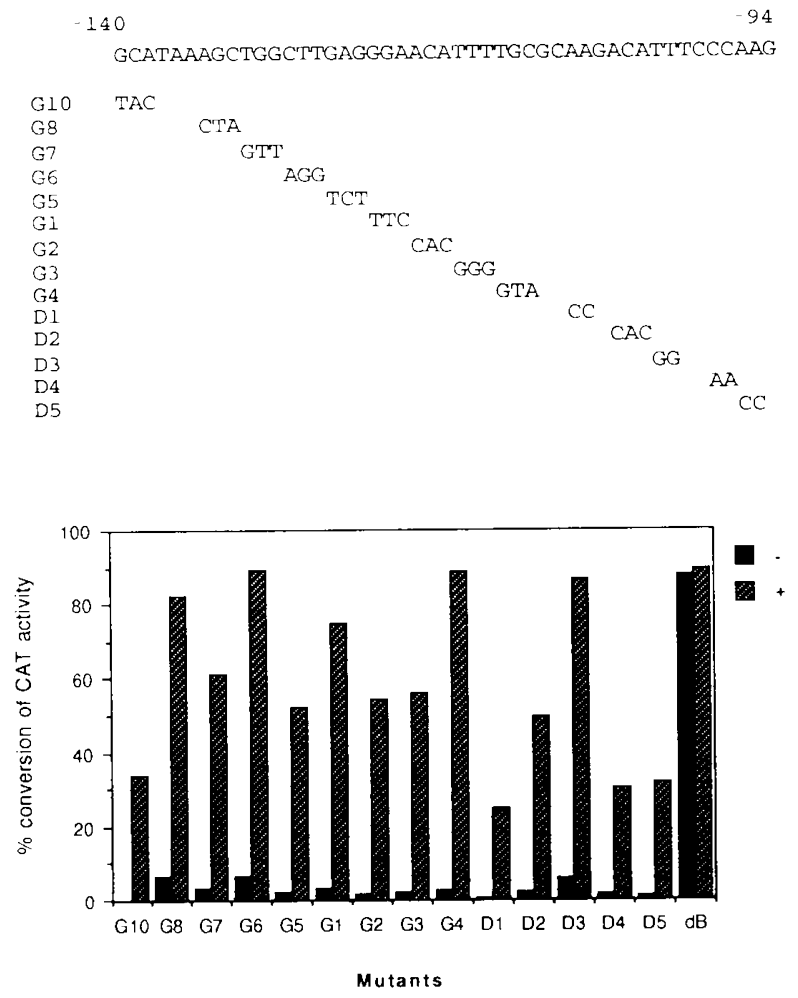

FIG. 3. Trans-activation of AGP gene by $Y Y 1$ is mediated by a $\mathrm{B}$ motif. Cotransfection assays of CMV-YY1 expression vector and mutated upstream regulatory sequence (spanning from -140 to -94 ) of the AGP gene linked to CAT reporter gene. The mutated sequences are shown in the upper panel. $\mathrm{dB}$ is the deleted mutant of the B motif linked to CAT, as reported in our earlier publication (Lee et al., 1993). The amounts of plasmid and the cells used for the transfection are the same as in Fig. 1. ( - and +$)$ Transfection in the absence and in the presence of CMV-YY1.

mutated AGP/CAT except the B-truncated mutant (Fig. 3, lower panel, dB). These data indicate that YY1 is unlikely dependent on a single motif spanning from -140 to -94 of AGP promoter for the activation. However, when the B-motif-deleted mutant was co-transfected with CMV-YY1, the activation was abolished (Fig. 3, dB). As detailed in our earlier publication (Lee et al., 1993), the B motif is a negative element that is recognized by factor $\mathrm{B}$. The CAT activity of B-motif-deleted mutant was substantially elevated as compared with the wild-type or other mutated AGP/CAT, consistent with the negative effect of the B motif. Having observed that YY1 could activate the AGP promoter but failed to do so when the B element was deleted, we initiated studies on the possible recognition of the B motif by YY1. Extensive experiments using a number of oligonucleotide probes and recombinant YY1 or YY1 purified from HepG2 failed to show that YYl can bind to the B motif (data not shown). These data suggest that the observed activation of YY 1 on the AGP promoter is unlikely to be mediated by direct interaction of $Y Y 1$ and the B element; rather, a functional interaction may be the likely explanation.

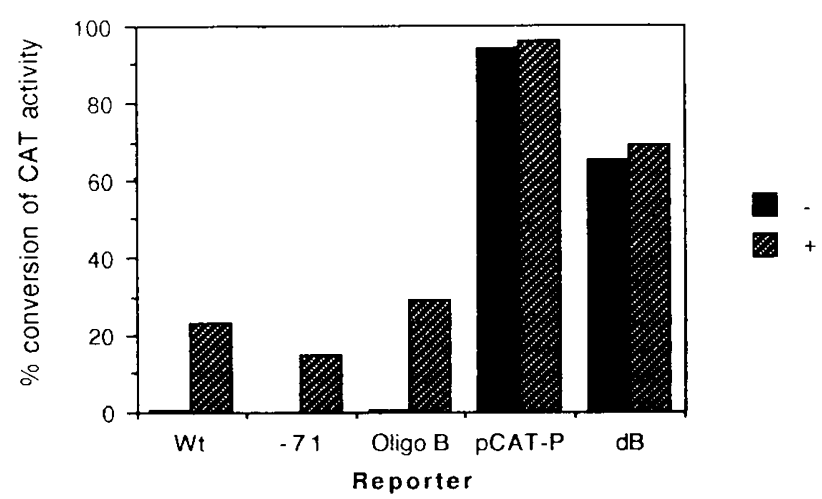

FIG. 4. Transfection assays demonstrate that the activation of AGP promoter function by $\mathrm{YY} 1$ is through the $\mathrm{B}$ motif. CAT reporter constructs containing the wild-type AGP promoter, deletion mutants of $B$ motif $(\mathrm{dB})$, and upstream of $-71(-71)$, oligomeric B motic (B10) linked to SV40 promoter-CAT (oligo B), and SV40 promoter-CAT (pCAT-P) were used for transfection $(-$ ) or cotransfection with CMV-YYI (+) into BHK cells. Reporter plasmid ( 10 $\mu \mathrm{g})$ and $3 \mu \mathrm{g}$ of CMV-YY 1 were used.

\section{$Y Y I$ can activate the $B$ motif linked to heterologous promoter}

The above experiments showed that the activation of YY 1 on the AGP promoter is mediated by the B element, but not by direct protein-DNA interactions. To address further the issue of how the $\mathrm{B}$ motif might mediate the activation of the AGP promoter by $\mathrm{YY} 1$, we constructed a heterologous promoter (SV40) containing oligomeric B sequences as well as -71 /AGP (upstream of -71 of AGP promoter was deleted) promoter linked to CAT (Lee et al., 1993). Wildtype and $-71 /$ AGP promoter CAT could be activated by CMV-YY1 (Fig. 4). YYl could also activate oligomeric B-linked heterologous promoters. In striking contrast to these data, YYl had no effect on promoters that do not contain the B element. Consistent with the conclusion that B is a negative element from previous studies, heterologous promoters containing oligomeric $\mathrm{B}\left(\mathrm{B}_{10}\right)$ element showed reduced activity. To rule out the possibility that there is a difference in transfection efficiency between experiments, we used $\mathrm{B}_{10}$-linked-pSV- $\beta$-Gal for the transfection and co-transfection assays. The $\mathrm{B}_{10}$-linked $\mathrm{pSV}-\beta-\mathrm{Gal}$ was much weaker than the pSV- $\beta$-Gal when staining with X-Gal (data not shown). However, when YY1 was co-transfected with $\mathrm{B}_{10}$-pSV- $\beta$-Gal, the $\beta$-Gal activity was elevated (data not shown). This increase in activity is not due to the increase in transfection efficiency when YY 1 was present, as evident by the apparent number of cells positive in X-Gal staining are relatively constant (data not shown). These data suggest that YY 1 is involved in modulating the factor B activity either by direct protein-protein or functional interaction with $\mathrm{B}$ factor or by repressing the expression of the $\mathrm{B}$ factor gene.

To rule out further any possible artefacts resulting from these cotransfection experiments, we constructed a YYl expression vector (CMV-C250) in which only protein containing the carboxy-terminal 250 amino acids could be expressed. The results from the cotransfection experiments 


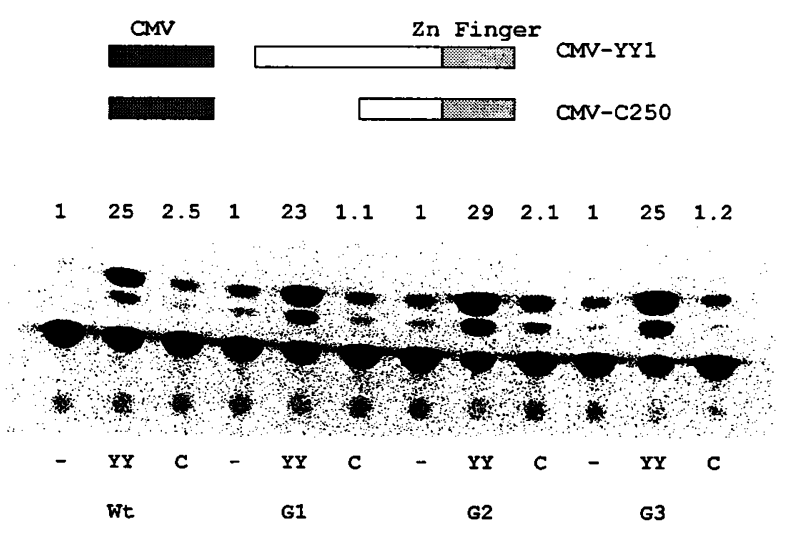

FIG. 5. The trans-activation of the AGP gene by YY1 requires the full-length YY1 molecule. The upper panel shows the construction of $\mathrm{YY} 1$ and the truncated $\mathrm{YY} 1$ expression vectors, CMV-YY1 and CMV-C250. The lower panel shows the trans- activation of AGP/CAT by CMVYY1 but not by CMV-C250. Cotransfection experiments were detailed in the legends of Figs. 1 and 2 . The numbers on top of the lower panel indicate the fold stimulation relative to the basal CAT activity of each CAT reporter construct (normalized to 1). (-) Transfection with the CAT reporter plasmid alone; (YY) cotransfection with CMV-YY1; (C) cotransfection with CMV-C250. Wild-type (wt) or mutant AGP-CAT (G1, G2, and G3) are shown on the bottom line of the lower panel.

demonstrated that when the animo-terminal portion of YYI was deleted, it failed to activate the AGP gene (Fig. 5). Taken together, the activation of the AGP gene by YY1 not only requires the B motif but also needs the amino-terminal portion of YYI molecule.

\section{YYI does not interfere with the binding of $B$ factor to its cognate motif}

Having demonstrated that YY1 can activate the AGP gene through the B motif, we would like to know whether YY1 interacted with the B factor physically. Purified YY1 (from liver) or recombinant $Y Y 1$ was incubated with rat liverderived B factor. Purified YY1 did not interfere with the B factor binding to its motif in footprinting analysis (data not shown) or in gel mobility-shift assay in the presence or absence of specific antibody to YY1 (data not shown). Purified AGP/EBP or protein derived from other column fractions behaved similarly. Furthermore, recombinant YYI did not inhibit the footprinting activity of B factor. These data indicated that $Y Y 1$ did not form a protein-protein complex with factor $B$; rather, it interacted with $B$ factor functionally without interfering with the DNA-binding activity of B factor.

\section{The level of YYI does not change during the acute-phase response}

We have shown previously that the levels of AGP/EBP (the most prominant positive factor) and $B$ factor (a negative factor) are induced and reduced during the acute-phase reaction (Change et al., 1990; Lee et al., 1993). This may account in part for the net induction of the acute-phaseresponse genes. Because we have now shown that YYl can activate the transcription of AGP gene, it would be interesting to examine the change in the protein level as well as the binding activity of YYl during the acute-phase response. Liver nuclear extracts were prepared from untreated or LPS-treated rats and used for gel retardation assays (using UCR oligonucleotide, which also contains an overlapping AGP/EBP-binding site) and Western blot analysis. Both the binding activity and the protein level of YYl remains constant whether pre- or post-acute-phase response (Fig. 6). AGP/EBP was increased during the acute-phase response, which was a nice internal control. Taken together, these data suggest that the protein level of YY1 does not change; however, its functional activity for interaction with $B$ factor may be elevated (e.g., through post-translational modification) during acute inflammation.

\section{DISCUSSION}

\section{Mechanism of activation of AGP gene by $Y Y I$}

In this paper we have demonstrated that $Y Y 1$ activates transcription directed by the AGP promoter or heterologous (SV40) promoter containing the negative element B. YY1 represses activity of the SV40 enhancer/promoter containing the YY1-binding motif (Shi et al., 1991). The fundamental difference between the YY1 motif-mediated and the B-motif-mediated activity of YY1 is the involvement of direct YY1-DNA interaction in the former case and only functional interaction of YY1 and B-motif in the latter case. Two lines of evidence suggest that the B motif of AGP promoter mediates YY1's activation of AGP gene: (i) the activation of AGP promoter by $Y Y 1$ depends on the presence of $B$ sequence; (ii) YYl can activate B-motif-mediated repression of SV40 promoter when the B motif is inserted into this promoter. An extensive search failed to reveal any DNA element in the AGP promoter region that can be recognized by YY1. How can the B sequence mediate the action of YY 1 without direct DNA-protein interaction? Because the B element was shown to be recognized by a negative transcription factor B (Lee et al., 1993), four possible mechanisms may exist: (i) direct $Y Y 1$ and factor $B$ interaction at the protein level resulted in the reduced repressor activity of $B$ factor; (ii) YYl could repress the expression of the B factor, resulting in a reduced protein level of factor $B$; (iii) there is only a functional interaction between YY1 and factor B without direct protein-protein interaction, e.g., modulating of factor B's activity by YY1; (iv) YY1 interacts with factor B functionally via an intermediary. For the first possibility, it could be a physical interaction between YY1 and factor B. For the second possibility, YY1 may bind to the cognate motif in the regulatory region of the factor $B$ gene and result in repression of expression of factor B. For the third possibility, YY1 may affect factor B's activity by modification of factor B post-translationally. For the fourth possibility, there may exist a corepressor for the interaction of $Y Y 1$ and factor B.

Two lines of evidence indicate that YY1 interacts with B factor functionally, but not physically (i.e., complex forma- 

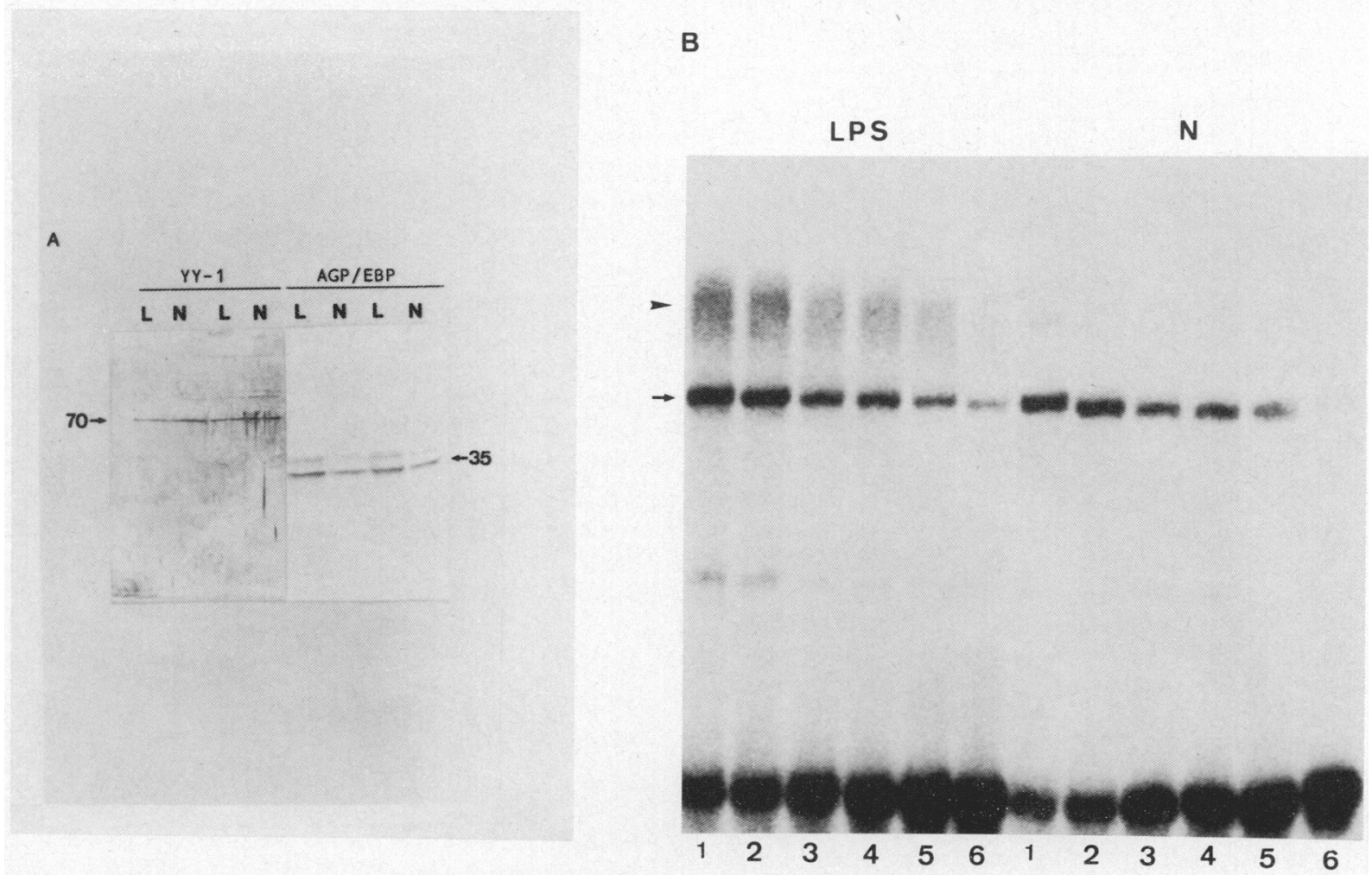

FIG. 6. Determination of the protein level and the DNA-binding activity of YY1 in the nuclear extracts prepared from normal and LPS-treated liver. A. Western blot analysis showing the relative constant protein level of YY1 in normal rat liver nuclear extract (N) and extract prepared from LPS-treated liver (LPS). Rabbit antibody to YY 1 was used for the blot analysis. The AGP/EBP level (indicated by a 35 and arrow) was used as a positive control to show its increase during the acute-phase response. B. Gel mobility-shift assay showing the constant level in binding activity of YY1 in normal liver nuclear extract and extract from liver of the acute-phase response (lanes $1-6$ contain $10,8,7,6,4$, and $2 \mu$ g of nuclear extract, respectively). The arrow indicates the YY1-DNA complex; the arrow head indicates the AGP/EBP- or AGP/EBP-related factors.

tion): (i) both purified and recombinant YYl cannot inhibit the footprinting activity of factor $B$, and antibody to $Y Y 1$ failed to pattern of complex formation in a bandshift assay; (ii) although YY1 cannot bind to the B motif, it can activate genes that contain a B motif. The following examples show that YY1 could affect gene expression through a third proteins: (i) YY1 repression of the P5 promoter is relieved by adenovirus E1A protein (Shi et al., 1991). (ii) A fusion protein of YY1 and the GAL4 DNA binding domain represses transcription of a thymidine kinase promoter with GAL4 binding sites (Seto et al., 1991). (iii) c-Myc can form complex with YY1 and thus modulates the activity of YY1 (Shrivastava et al., 1993). A simple model to explain the functional versatility of YY1 is that its interaction with different cellular proteins may alter its activity. During the acute-phase response, the binding activity of factor $B$ decreases while both the protein level and the DNA-binding activity of YY1 do not change. The activity of YY1 can be modulated during the acute inflammation in such way so that its functional interaction with factor $B$ is enhanced, while the DNA-binding activity of factor B is unaffected. However, this modification of YY1's activity, which ultimately affects the activity of factor B, may not involve in the formation of YY1-B complex. Alternatively, factor B is modified during the acute-phase response and results in the enhanced func- tional interaction with YY1. Furthermore, both of these possibilities exist. Future experiments should be designed to resolve this issue.

A number of systems in which protein-protein interactions resulted in altered functions of a specific transcription factor have been demonstrated (Lee et al., 1993; Nishio et al., 1993; Stein et al., 1993). The functions of YYl are mediated mainly by its binding to a specific DNA motif (Hariharan $e t$ al., 1991; Gualberto et al., 1992; Montalvo et al., 1991; Park and Atchison, 1991; Seto et al., 1991; Shi et al., 1991; Bauknecht et al., 1992; Flanagan et al., 1992; Lee et al., 1992). Therefore, YY1 may also modulate the expression of factor $B$ transcriptionally through its binding to the regulatory regions of factor B gene. Definitive answers must wait until the factor $B$ gene is isolated and cloned. Taken together, our present data and the rapid reaction during the acute inflammation suggest that the functional interaction of YY1 and factor $B$, rather than the transcriptional mechanism is the more likely mechanism in modulating the factor B activity. However, despite vigorous tests (performed by anti-YY1 antibody depletion followed by footprinting assay or the use of anti-YY1 antibody in gel mobility-shift assay), we have failed to demonstrate that the YY1 and factor B complex exists.

One of the most dramatic features of AGP gene regulation 


\section{TRANSCRIPTION OF AGP GENE}

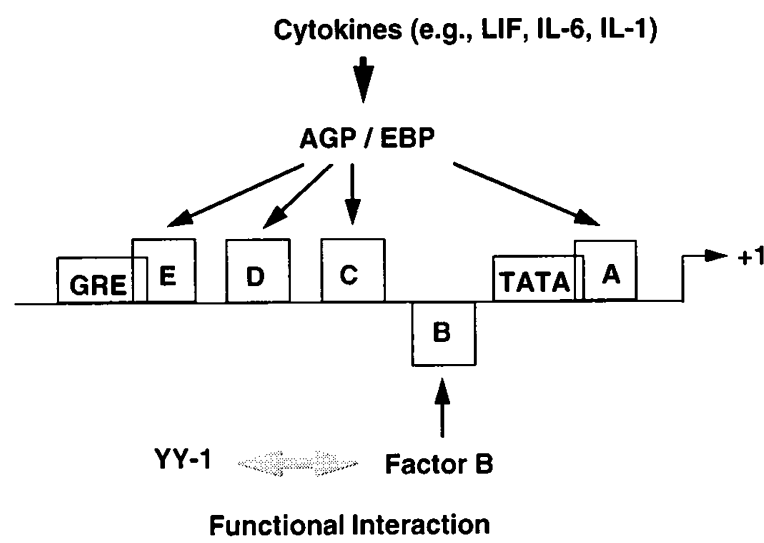

FIG. 7. Schematic representation of the regulation of AGP gene by various transcription factors. Cytokines stimulate AGP/EBP- or AGP/EBP-related trans-activators and result in the induction of AGP during the acute-phase response. YY 1 participates in the AGP regulation by repressing the functional activity of a negative factor, B. Thus, YY1 activates AGP gene indirectly by functional interaction with factor B.

is its induction during the acute-phase response. We have previously shown the level of AGP/EBP increased several fold during the acute-phase response. We also documented a decrease in the binding activity of factor B. In this report, we presented evidence for the activation of AGP gene by YY1, including that (i) this activation is mediated by B motif; (ii) the activation of AGP gene by YY1 requires the aminoterminal portion of YYl molecule; and (iii) YYl's function in activating AGP gene is independent of AGP/EBP.

Both the protein level and the binding activity of YY1 do not change in rat liver during the acute-phase response (Fig. 6). Because the mechanism of reduction of factor B's binding activity during the acute-phase response remains to be solved, it is highly possible that some post-translational mechanisms are involved in regulating factor B's activity, such as interacting with YY 1 . If this indeed happens, then the functional activity of YY1 under normal physiological conditions must be different from that during the acute-phase response. The regulatory role of YY1 on factor B's level or activity offers an attractive model for gene regulation: Regulation of a negative factor by another negative/positive (Yin-Yang-1) factor. A schematic mode summarizing the regulation of AGP gene is presented in Fig. 7.

\section{Additive effect of activation by $Y Y 1$ and $A G P / E B P$ on the AGP promoter}

We have shown previously that AGP/EBP could activate AGP transcription and that AGP/EBP is the key nuclear factor in conveying the signals [i.e., cytokines like interleukin-1 (IL-1), IL-6, or leukemia inhibitory factor] to their target genes (e.g., AGP) during the acute-phase response. To determine whether the activation effects of AGP/EBP and YY1 on AGP are independent events, we performed transfection experiments using wild-type AGP/CAT, CMV-AGP/ EBP, and CMV-YY1. As shown in Fig. 2, AGP/EBP and YY1 could activate the AGP promoter, and the effect of these two expression vectors seems to be additive. These data suggest that AGP/EBP and YY1 do not interact with one another to activate the AGP gene, but rather act independently in activiating the AGP gene. These results are consistent with the data that the activity of YY1 depends on the B motif whereas AGP/EBP depends on other motifs. Taken together, YY1, AGP/EBP, $\mathrm{C} / \mathrm{EBP}-\alpha$, and factor $\mathrm{B}$ are important trans-acting factors in regulating AGP gene transcription. The data present in this paper are particularly important in the potential modulation of YYl's activity during the acute inflammation and its subsequent interaction with factor B. Further understanding along these lines may clarify not only factor B's regulation but also YYl's mode of action and regulation.

\section{ACKNOWLEDGMENTS}

We thank Dr. Tung-Tien Sun for a critical review of the manuscript, Mr. Tso-pang Yao for performing the PCR of YY1 cDNA, Dr. Wuh-Liang Hwu for technical help, WenHai Tsai for nuclear extracts, and Drs. T. Shenk for CMVYY 1 and $\mathrm{K}$. Ozato for the expression vector of UCRBP. This research was supported by grants NSC82-0412-B002-25 I from the National Science Council.

\section{REFERENCES}

BAUKNECHT, T., ANGEL, P., ROYER, H.D., and ZUR HAUSEN, H. (1992). Identification of a negative regulatory domain in the human papillomavirus type 18 promoter: interaction with the transcriptional repressor YY1. EMBO J. 11, 4607-4617.

BAUMANN, H., and HELD, W.A. (1981). Biosynthesis and hormone-regulated expression of secretory glycoproteins in rat liver and hepatoma cells. J. Biol. Chem. 256, 10145-10155.

BAUMANN, H., and MAQUAT, L.E. (1986). Localization of DNA sequences involved in dexamethasone-dependent expression of the rat alpha- 1 acid glycoprotein gene. Mol. Cell. Biol. 6, 2551-2561.

BAUMANN, H., FIRESTONE, G.L., BURGESS, T.L., GROSS, K.W., YAMAMOTO, K.R., and HELD, W.A. (1983). Dexamethasone regulation of alpha-1 acid glycoprotein and other acute phase reactants in rat liver and hepatoma cells. J. Biol. Chem. 258, 563-570.

BAUMANN, H., HILL, R.E., SAUDER, D.N., and JAHREIS, G.P. (1986). Regulation of major acute phase plasma proteins by hepatocyte stimulating factors of human squomas carcinoma cells. J. Cell Biol. 102, 370-383.

BENNETT, H., and SCHMID, K. (1980). Immunosuppression of human plasma alpha-1 acid glycoprotein: Importance of the carbohydrate moiety. Proc. Natl. Acad. Sci. USA 77, 61096113.

CHANG, C.J., CHEN, T.T., LEI, H.Y., CHEN, D.S., and LEE, S.C. (1990). Molecular cloning of a transcription factor, AGP/ EBP, that belongs to members of the C/EBP family. Mol. Cell. Biol. 10, 6642-6653. 
DARLINGTON, G.D., WILSON, R., and LACHMAN, L.B. (1986). Monocyte-conditioned medium, interleukin-1, and tumor necrosis factor stimulate the acute phase response in human hepatoma cells in vitro. J. Cell Biol. 103, 787-793.

FLANAGAN, J.R., BECKER, K.G., ENNIST, D.L., GLEASON, S.L., DRIGGERS, P. H., LEVI, B.Z., APPELLA, E., and OZATO, K. (1992). Cloning of a negative transcription factor that binds to the upstream conserved region of Moloney murine leukemia virus. Mol. Cell. Biol. 12, 38-44.

FRASCH, M., and LEVINE, M. (1987). Complementary patterns of even-skipped and fushi tarazu expression involve their differential regulation by a common set of segmentation genes in Drosophila. Genes \& Dev. 1, 981-995.

FRIEDMANN, M.L. (1983). Control of malaria virulence by alpha- 1 acid glycoprotein (orosomucoid), an acute phase (inflammatory) reactant. Proc. Natl. Acad. Sci. USA 80, 5421-5424.

GAULDI, J., RICHARDS, C., HARNISH, D., LANDSORP, P., and BAUMANN, H. (1987). Interferon beta-2 shares identity with monocyte derived hepatocyte-stimulating factor and regulates the major acute phase protein response in liver cells. Proc. Natl. Acad. Sci. USA 84, 7251-7255.

GORSKI, K., CARNEIRO, M., and SCHIBLER. U. (1986). Tissue-specific in vitro transcription from the mouse albumin promoter. Cell 47, 767-776.

GUALBERTO, A., LePAGE, D., PONS, G., MADER, S.L., PARK, K., ATCHISON, M.L., and WALSH, K. (1992). Functional antagonism between $Y Y 1$ and the serum response factor. Mol. Cell. Biol. 12, 4209-4214.

HARIHARAN, N., KELLEY, D.E., and PERRY, R.P. (1991). Delta, a transcription factor that binds to downstream elements in several polymerase II promoters, is a functionally versatile zinc finger protein. Proc. Natl. Acad. Sci. USA 88, 9799-9803.

KLEIN, E.S., DILORENZO, D., POSSECKERT, G., BEATO, M., and RINGOLD, G.M. (1988). Sequences downstream of the glucocorticoid regulatory element mediate cycloheximide inhibition of steroid-induced expression from the rat alpha-1 acid glycoprotein promoter: evidence for a labile transcription factor. Mol: Endocrinol. 2, 1343-1351.

KULKARNI, A.B., REINKE, R., and FEIGELSON, P. (1985). Acute phase mediators and glucocorticoids elevate alpha- 1 acid glycoprotein gene transcription. J. Biol. Chem. 260, 1538615389.

LEE, J.S., GALVIN, K.M., and SHI, Y. (1993). Evidence for physical interaction between the zinc-finger transcription factor YY1 and Sp1. Proc. Natl. Acad. Sci. USA 90, 6145-6149.

LEE, T.C., SHI, Y., and SCHWARTZ, R.J. (1992). Displacement of BrdUrd-induced YY1 by serum response factor activates skeletal alpha-actin transcription in embryonic myoblasts. Proc. Natl. Acad. Sci. USA 89, 9814-9818.

LEE, Y.M., TSAI, W.H., LAI, M.Y., CHEN, D.S., and LEE, S.C. (1993). Induction of liver alpha-1 acid glycoprotein gene expression involves both positive and negative transcription factors. Mol. Cell. Biol. 13, 432-442.

LICHT, J.D., GROSSEL, M.J., FIGGE, J., and HANSEN, U.M.
(1990). Drosopkila Krüppel protein is a transcriptional repressor. Nature 346, 76-79.

LIU, H. TAKAGAKI, M.K., and SCHMID, K. (1988). In vitro nerve-growth-promoting activity of human plasma alpha-1 acid glycoprotein. J. Neurosci. Res. 20, 64-72.

MONTALVO, E.A., SHI, Y., SHENK, T., and LEVINE, A.J. (1991). Negative regulation of the BZLF1 promoter of EpsteinBarr virus. J. Virol. 65, 3647-3655.

NISHIO, Y., ISSHIKI, H., KISHIMOTO, T., and AKIRA. S. (1993). A nuclear factor for interleukin-6 expression (NF-IL6) and the glucocorticoid receptor synergistically activate transcription of the rat $\alpha-1$ acid glycoprotein gene via direct protein-protein interaction. Mol. Cell. Biol. 13, 1854-1862.

PARK, K. , and ATCHISON, M.L. (1991). Isolation of a candidate repressor/activator, NF-E1 (YY-1, delta), that binds to the immunoglobulin $k$ ' 3 ' enhancer and the immunoglobulin heavy-chain uE1 site. Proc. Natl. Acad. Sci. USA 88, 9804-9808.

PROWSE, K.R., and BAUMANN, H. (1988). Hepatocyte-stimulating factor, beta-2-interferon, and interleukin-1 enhance expression of the rat alpha-1 acid glycoprotein gene via a distal upstream regulatory region. Moll. Cell. Biol. 8, 42-51.

RUPPERT, J.M., KINZLER, K.W., WONG, A.J., BIGNER, S.H., KAO, F.T., LAW, F.L., SEUANEZ, H.N., O'BRIAN, S.J., and VOGELSTEIN, B. (1988). The GL1-Krüppel family of human genes. Mol. Cell. Biol. 8, 3104-3113.

SETO, E., LEWIS, B., and SHENK, T. (1993). Interaction between transcription factors $\mathrm{Spl}$ and $\mathrm{YY} 1$. Nature 365, 462-464.

SETO, E., SHI, Y., and SHENK, T. (1991). YY1 is an initiator sequence-binding protein that directs and activates transcription in vitro. Nature 354, 241-245.

SHI, Y., SETO, E., CHANG, L.S., and SHENK, T. (1991). Transcriptional repression by YY-1, a human GL1-Krüppelrelated protein, and relief of repression by adenovirus E1A protein. Cell 67, 377-388.

SHRIVASTAVA, A., SALEQUE, S., KALPANA, G.V., ARTANDI, S., GOFF, S.P., and CALAME, K. (1993). Inhibition of transcriptional regulator Yin-Yang-1 by association with c-Myc. Science 262, 1889-1892.

STEIN, B., COGSWELL, P.C., and BALDWIN, A.S. (1993). Functional and physical associations between NF- $\mathrm{B}$ and $\mathrm{C} / \mathrm{EBP}$ family members: A Rel domain-bZIP interaction. Mol. Cell. Biol. 13, 3964-3974.

Address reprint requests to: Dr. Sheng-Chung Lee

- Institute of Molecular Medicine College of Medicine

National Taiwan University Taipei, Taiwan

Received for publication March 22, 1994, and in revised form May 24, 1994. 